CASE REPORTS

\title{
Non-traumatic clostridial myositis: an unusual feature of brain death
}

\author{
J. P. THYS \\ M.D.
}

\author{
P. ECTORS \\ M.D.
}

\author{
P. NOEL \\ M.D. \\ The Medical Intensive Care Unit, University Hospital of St Pierre, Brussels, Belgium
}

\begin{abstract}
Summary
In a case of brain death, a Clostridium sordellii and Escherichia coli septicaemia-of probable gastrointestinal origin - developed and was associated with a diffuse clostridial myositis. Factors responsible for the initiation and development of this unusual clostridial infection are discussed.
\end{abstract}

\section{Introduction}

Two patterns of non-traumatic clostridial tissue infections can be distinguished. The first one, which is relatively common, consists of visceral anaerobic cellulitis, with or without contiguous spread to the adjacent muscles. In the latter case, primary intraabdominal infection can spread directly to the abdominal wall or, along the retroperitoneal tissue planes including the psoas muscles, spread to the lower extremity (Mzabi, Himal and MacLean, 1975; Hitchcock and Bubrick, 1976). The second type of spontaneous clostridial tissue infection, which is quite unusual, is metastatic myositis due to a muscular seeding during a clostridial septicaemia arising from a site distant from the muscular lesion.

A case is reported of spontaneous gas gangrene with clostridial septicaemia occurring in a young patient with brain death due to an alcoholic intoxication.

\section{Report of a case}

One New Year's Eve, a usually sober 18-year-old drank in a short time $26 \mathrm{oz}$ of whisky and an indefinite number of pints of beer: he was found unconscious on a chair approximately $15 \mathrm{~min}$ later. He was immediately sent to St Pierre's Hospital, Brussels, where a cardio-respiratory arrest was observed. Resuscitation manoeuvres restored BP to $90 \mathrm{mmHg}$ within a few minutes, but the patient remained unconscious without any spontaneous respiration. Two hours after admission, the patient

Correspondence: J. P. Thys, M.D., Department of Internal Medicine, University Hospital of St Pierre, rue Haute 322, B-1000 Brussels, Belgium. was in deep coma with no reaction to painful stimuli; the pupils were dilated and fixed to light; the corneal responses were absent; he remained apnoeic and the rectal temperature was $34^{\circ} \mathrm{C}$; the diuresis was 70 $\mathrm{ml} / \mathrm{hr}$ but the patient became anuric a few $\mathrm{hr}$ later. The treatment consisted of respiratory maintenance, plasma expanders, alkalinization, intravenous frusemide and dexamethasone. No i.m. injection was given.

Twenty-four hours after admission, the clinical status remained unchanged: brain death was assessed by the absence of brain-stem function and isoelectric electroencephalogram. The stools were stained with fresh blood. The blood tests were as follows: urea $22.7 \mathrm{mmol} / 1$; creatinine $707.2 \mu \mathrm{mol} / 1$ (at admission, $141.4 \mu \mathrm{mol} / \mathrm{l}$ ); pH 7.20; lactate 6.8 $\mu \mathrm{mol} / \mathrm{l}$; potassium $6.7 \mathrm{mmol} / \mathrm{l}$; SGOT 5160 i.u.; SGPT 1700 i.u.; creatine phosphokinase 20000 i.u.; amylase 750 Street-Close u./dl (normal <33 u./dl). The alcoholaemia was $280 \mathrm{mg} / \mathrm{dl}$ approximately $4 \mathrm{hr}$ after ingestion.

On the second day, fever and deep shock developed. A few hours later, generalized muscle oedema appeared, most pronounced in the left thigh and in the back where the skin presented cyanotic marblings. Gaseous crepitation was present in the same areas; an X-ray film (Fig. 1) revealed extensive soft tissue gas in the thigh. During a left quadriceps biopsy, foul-smelling gas escaped from the aponeurotomy; the muscle appeared dark with gelatinous oedema but was not visibly necrotic; Clostridium sordellii was isolated from this muscle sample as well as from the 2 blood cultures, one of which also revealed an Escherichia coli. The patient died $48 \mathrm{hr}$ after admission. Post-mortem examination confirmed a diffuse oedematous myositis and acute necrotic-haemorrhagic pancreatitis.

\section{Discussion}

In this case, acute alcoholic intoxication induced a cardio-respiratory arrest and consequent brain death. A muscular oedematous swelling with 
crepitations, characteristic of gas gangrene, was observed: this diffuse myositis was attributed to a C. sordellii septicaemia assessed by blood and muscle cultures.

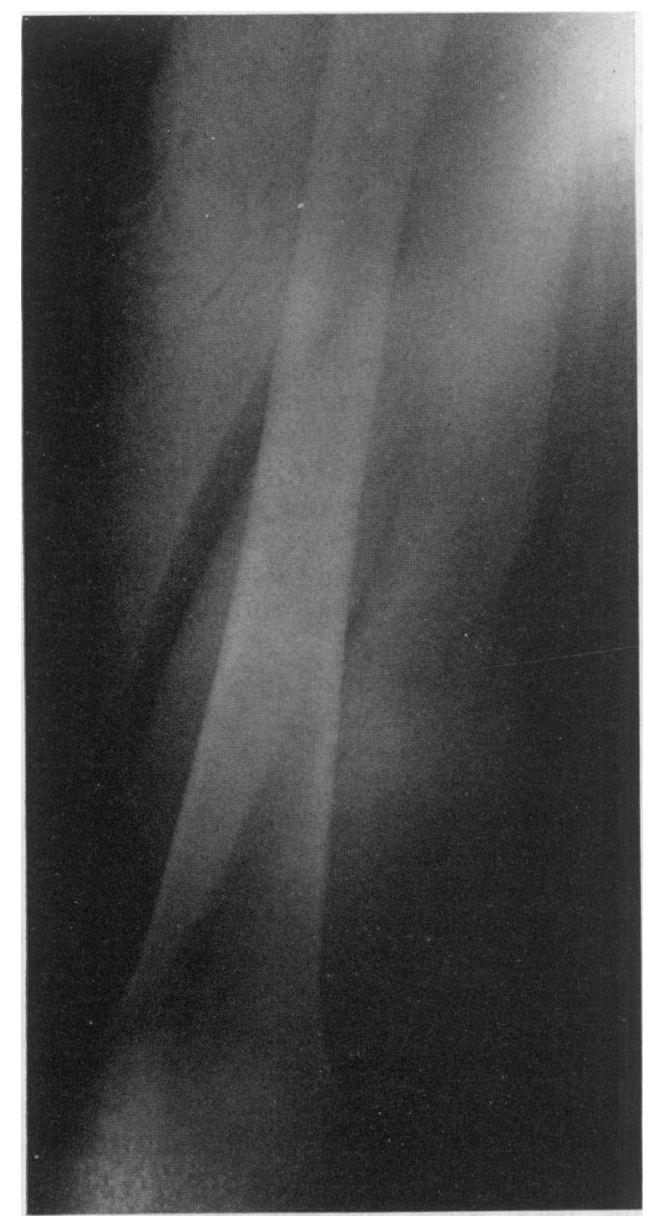

FIG. 1. X-ray of the left thigh demonstrating muscle oedema and intramuscular gas.

Clostridial septicaemias of non-traumatic origin are not rare but septic muscular involvement in this condition is quite unusual: Jendrzejewski et al. (1978) recently reported 2 cases and reviewed 8 other cases. In 7 of these 10 cases, ulcerative lesions of the gastrointestinal tract were present: most often, carcinomas were found but focal necrosis or inflamed areas of the intestinal mucosa associated with haematological or lymphoproliferative disorders were described (Congeni and Nankervis, 1976; Jendrzejewski et al., 1978). Such breaks in the intestinal mucosa probably allowed normal faecal flora access to the blood stream. In the present patient, gastrointestinal lesions could be inferred from the emission of bloody faeces; they could result from necrotico-haemorrhagic pancreatitis $\frac{\varrho}{3}$ or from cerebral brain damage (Bogoch, 1974).

MacLennan (1962) suggested that slight local $\stackrel{c}{c}^{\circ}$ tissue injury might lead to the metastatic foci of clostridial myositis in the case of septicaemia. $\stackrel{?}{+}$ Previous muscle injury has been noted in the same? site of spontaneous myositis, probably related to 흥 clostridial septicaemia (Valentine, 1957; Engeset $\frac{\bar{s}}{\frac{5}{\sigma}}$ et al., 1973; Jendrzejewski et al., 1978). In the $\varrho$ present patient, muscular lesions-as shown by increased muscle enzymes and the very rapid rise $\vec{\circ}$

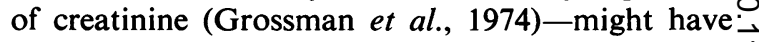
resulted from circulatory arrest and persistent $\vec{\omega}$ shock with muscle anoxia and partial anaerobiosis: such conditions decrease oxydo-reduction potentiako in which Clostridium sp. could grow and produce myositis. The position of the patient when found unconscious could account for asymmetrical body compression and asymmetrical muscular involvement.

Systemic factors seem to be very important in the $\vec{\circ}$ pathogenesis of spontaneous clostridial infections. Nine of the 10 patients reviewed by Jendrzejewski ${ }_{\vec{C}}$ et al. (1978) presented debilitated states or malignancies. Cancer as well as cytostatic and immuno- $\vec{\bullet}$ suppressive therapy are often cited as predisposi@g $\mathscr{\circ}$ factors to Clostridium septicaemia (Smucker, Reid. and Harding, 1960; Cabrera, Tsukada and Pickrêิ; 1965; Wynne and Armstrong, 1972; Mzabi, et a尹, 1975). In addition to the epithelial break due to the neoplasia or its treatment, the metabolic and $\frac{0}{\infty}$ immunological changes associated with neoplasia $\varrho$ may contribute to create a local environment $\overrightarrow{\vec{O}}$ favourable to infection. Likewise, diabetes has been 3 found related to non-metastatic spontaneous clostridial myositis (Soscia and Grace, 1965; Mzabi, et al., 1975). Surprisingly, cancer chemotherapy ando diabetes do not seem to be frequently associated with clostridial myositis arising at a site distant from a visceral lesion (Jendrzejewski et al., 1978). None of these associated factors were present in this patient $\frac{}{}$ who was in good health until the terminal event.

C. sordellii usually associated with other Clostri-을 dium spp. has been shown to be an unusual causative micro-organism of gas gangrene in man; it has rarely been found as the unique pathogen in that ${ }_{\sigma}$ disease: in such cases, muscular lesions with s $^{-}$ gelatinous oedema without obvious necrosis haveN been described previously (MacLennan, 1962; 范 Browdie et al., 1975).

\section{Acknowledgments}

We are grateful to Doctor S. Finegold (Los Angeles, U.S.A.) ${ }_{-}^{-}$ who identified the Clostridium sp. and to Professor W. H. Brummelkamp, Amsterdam, The Netherlands, for his helpful comments. 


\section{References}

BoGoCH, A. (1974) Hematemesis and melena. In: Gastroenterology (Ed. by Bockus, H.L.) 3rd Edn, Vol. 1, p. 763. W. Saunders Co., Philadelphia.

Browdie, D.A., Davis, J.H., Koplewitz, M.J., Corday, L. \& LeADBeTter, A.W. (1975) Clostridium sordellii infection. Journal of Trauma, 15, 515.

Cabrera, A., Tsukada, Y. \& Pickren, J.W. (1965) Clostridial gas gangrene and septicemia in malignant disease. Cancer, 18, 800.

Congeni, B.L. \& NANkervis, G.A. (1976) Clostridium septicum bacteremia in a patient with aplastic anemia. Journal of Pediatrics, 89, 331.

Engeset, J., Macintyre, J., Smith, G. \& Welch, G. (1973) Clostridium welchii infection: an unusual case. British Medical Journal, $2,91$.

Grossman, R.A., Hamilton, R.W., Morse, B.M., Penn, A.S. \& GoldBerG, M. (1974) Non-traumatic rhabdomyolysis and acute renal failure. New England Journal of Medicine, 291, 807.

Hitchсоск, C.R. \& Bubrick, P. (1976) Gas gangrene infections of the small intestine, colon and rectum. Diseases of the Colon and Rectum, 19, 112.

JENDRZEJEWSKI, J.W., JONES, S.R., NEWCOMBE, R.L. \& GILBERT, D.N. (1978) Non-traumatic clostridial myonecrosis. American Journal of Medicine, 65, 542.

MaClennan, J.D. (1962) The histotoxic clostridial infections of man. Bacteriological Review, 26, 177.

Mzabi, R., Himal, H.S. \& Maclean, L.D. (1975) Gas gangrene of the extremity: the presenting clinical picture in perforating carcinoma of the caecum. British Journal of Surgery, 62, 373.

Smucker, E.E., Reid, S.E. \& Harding, H.B. (1960) Spontaneous fatal gas gangrene septicemia. Journal of the American Medical Association, 174, 898.

Soscia, J. \& Grace, W.J. (1965) Gas bacillus infections: two unusual cases. American Journal of Digestive Diseases, $10,625$.

VALENTINe, J.C. (1957) Gas gangrene septicaemia due to carcinoma of the caecum and muscular trauma. British Journal of Surgery, 44, 630.

WYNNE, J.W. \& ARMSTRONG, D. (1972) Clostridial septicemia. Cancer, 29, 215. 